\title{
Application of TBL Teaching Method in College Medical Chinese Teaching
}

\author{
Tao Cui ${ }^{1}$, Fei Yang ${ }^{2}$ \\ ${ }^{1}$ Foreign Language Department, Qiqihar Medical University, Qigihar, Heilongjiang, 161006, China \\ ${ }^{2}$ Department of Pediatrics, The Third Affiliated Hospital of Qiqihar Medical University, Qigihar \\ Heilongjiang, 161002,China
}

Keywords: TBL teaching method, Medical teaching, Application exploration, Talent training

\begin{abstract}
As Chinas economic development level keeps improving, medical education develops and advances rapidly. Traditional teaching method cannot adapt medical talent training demand. The primary task of colleges is to reform teaching method and make talent training more flexible and efficient. Each medical college starts to actively explore and apply new teaching methods and teaching modes, such as TBL teaching method and PBL teaching method. All these methods are the research and discussion emphases of educators. This paper will analyze the application of TBL teaching method in college medical teaching so as to show this teaching method plays an important role in training medical talents.
\end{abstract}

\section{Introduction}

At present, as a new round of medical education reform is implemented, many medical education workers realize that the improvement of teaching quality and teaching efficiency needs innovative teaching method and thinking. Significant effect has been gained through continuous exploration and practice. As teaching reform deepens, traditional lecture-based teaching method cannot adapt current teaching demand. On this basis, situational teaching method and case teaching method are introduced. In western counties, PBL and TBL teaching methods are also applied in teaching reform, which triggers new reform tide. In view of the differences in teaching contents and objects, traditional teaching method no linger adapts teaching needs of medical colleges. Thus, it is necessary to realize advantages and disadvantages of teaching methods and choose teaching methods flexibly so as to reach the purpose of "teaching" and "doubt solving” . Next, this paper will analyze advantages, features and specific application of LBL, TBL and PBL teaching methods.

\section{LBL Teaching Method}

LBL (Lecture Based Learning) as a lecture-based teaching method can highlight the dominant position of teachers and take course teaching as the center to infuse knowledge in class teaching process. Such teaching method still prevails in colleges.

\section{Advantage of LBL Teaching Method}

Firstly, LBL teaching method saves and optimally utilizes teaching resources. Usually, LBL teaching method takes large class as a unit, and each class is taught by a teacher, which can save teaching human resource and relieve the shortage of faculty. Secondly, LBL teaching method keeps knowledge instruction continuity and accuracy. LBL teaching method can give full play to the prominent position of teachers and make teachers professional knowledge fully integrated and utilized. In this way, teachers will more comprehensively, accurately and deeply teach and analyze contents. The knowledge is taught to students, and instruction is more continuous and systematic. The requirement for students basic ability is low. LBL teaching method always highlights students dominant position and fully utilizes teachers professional knowledge. Hence, teachers can teach knowledge more comprehensively and systemically, while knowledge instruction is more continuous and specific. The application of modern technology makes teaching richer. Multimedia teaching is the most important teaching assistance means. Many colleges reduce course making time and 
improve course efficiency in order to make teaching more vivid and real. Meanwhile, internet can help teaching content to become richer and more diversified. Internet can be used to search many pictures, cases and video resources so that course teaching is vivid. In this way, students can deepen understanding of knowledge and their enthusiasm can be fully mobilized. As well, teaching atmosphere can be enhanced.

\section{Limitation of LBL Teaching Method}

Firstly, LBL teaching method cannot fully mobilize students enthusiasm. LBL teaching method always deems teachers as the subject and regards knowledge as the communication subject. Teachers can place the key point in knowledge communication during teaching, but many teachers will explain a lot of knowledge that students cannot digest in the limited classroom time in order to complete the teaching task as soon as possible. Thus, cramming education phenomenon appears, which is very adverse to mobilizing students enthusiasm and makes students generate boredom. Thus, cramming education becomes a limitation. Secondly, it is very unfavorable to train students independent thinking ability. The application of LBL teaching method is very passive. Students passively receive knowledge most often. Teachers will help students answer doubts as soon as they encounter problems. Thus, students exertion space is very small. As time goes, students will excessively depend on teachers. In one word, LBL teaching method cannot mobilize students enthusiasm, and teachers become the subject, so it is also called “cramming” teaching. It is disadvantageous to train students independent ability and operational ability and it is inconsistent with current innovative talent training objective. Students ability to apply knowledge is weakened. Medical science is a discipline with strong applicability. Many theories are based on practical service operation, while LBL teaching method lays emphasis on explaining knowledge points, overemphasizes the ability of taking examinations and pays attention to knowledge application. Besides, disciplines are excessively separated, and horizontal and vertical connections are few. Practical clinical work involves multiple disciplines. If students only own single clinic knowledge, they are difficult to carry out medical treatment work.

Even if LBL teaching method has many defects and is not accepted by all, it still has reference value in teaching. Teachers should combine specific conditions and teaching contents to flexibly chose and apply this teaching method. Students autonomous learning ability is poor, so this method can be used. But if the ability of teaching objects is outstanding, students innovation ability will be restricted, which is adverse to mobilizing learning potential.

\section{TBL Teaching Method}

TBL (Task based Learning) is centered by specific problem for teaching, and students are divided in different groups and learn according to the problem. It isalso called task-based learning method. This teaching method was proposed by Larry K Michaelsen in 2002. It is a new teaching mode based on teamwork. The foundation is teamwork. It assists teachers in teaching and helps students discuss. The basic teaching process is as follows: students self-study before class - students self-study in class - classroom learning examination (group discussion, summarize summary and make a speech by the representative) - intensive explanation by the teacher - class assignment (intra-group mutual evaluation). This process aims to examine students classroom performance and classroom learning initiative. Students assessment will be more comprehensive through classroom quiz, group discussion and mutual evaluation. TBL teaching method is based on PBL teaching method. Through continuously optimizing and developing PBL teaching method, TBL teaching method with diversified functions finally forms. To some extent, PBL teaching method makes $\mathrm{u}$ for the shortcomings of TBL teaching method.

\section{Advantage of TBL Teaching Method}

TBL teaching method can carry out teaching by multiple forms. It attaches great importance to students active learning and teamwork and expands learning in interactive teaching process. It can train students clinical medicine skills and consolidate basic knowledge. Thus, it really achieves dual training of basic theory and skills. In addition, TBL teaching method is based on team. In the team, 
students can express their opinions and problem solving thought at will, which enhances their interpersonal communication ability and independent problem solving ability.

\section{Defect of TBL Teaching Method}

TBL teaching method has its own advantages, but also has many defects. The use of this method will consume too much time and the method has strict requirement for students quality and ability. Compared with PBL, TBL teaching method owns very small inclination, and inclination span is also low. Meanwhile, it has low requirement for students ability. Thus, implementation difficulty of PBL teaching method is lower, and its scope of application is relatively wider. Even if TBL teaching method lays emphasis on basic knowledge, it is greatly limited by class hour, and the knowledge quantity taught by teachers is very restricted. Besides, students knowledge cognition and comprehension degree is low. PBL and TBL teaching methods differ in contents and implementation difficulty. PBL teaching method takes the case as application center, and has high basic requirements for students. It is applicable to clinic students with theoretical basis, while TBL teaching method has low interdisciplinary degree and has low basic requirements for students. It is suitable for medical students in different stages.

TBL teaching method lacks teaching materials that it can follow

The major function of teaching materials is for students study and assist students. Teaching materials are also important references for students. The quality of teaching materials will influence learning effect to some extent. Thus, the Ministry of Education pays much attention to teaching material construction. At present, there is lack of TBL teaching material in the market. But through continuous efforts of Ministry of Education, the first draft of pathology PBL teaching material has been basically completed. It will facilitate TBL teaching material construction. But, teaching material construction still has a long way to go and requires joint efforts of education sector and scientific research personnel.

TBL teaching method lacks scientific and effective evaluation system

TBL teaching method as a new teaching method lays emphasis on connecting theory and practice. Its application is still in the initial stage and fails to be popularized in a large scale. In terms of evaluation, there is short of scientific and effective method. How to better generalize TBL teaching method becomes a key content. Besides, TBL teaching method needs to own the ability to adapt teaching environment. Students should be facilitated to transform from traditional teaching idea and actively adapt TBL teaching method. Meanwhile, application effect of TBL teaching method should be objectively analyzed and evaluated. All these need to be enhanced by TBL teaching method in future.

TBL teaching method has high implementation cost and limited teaching resource

TBL teaching method extends many contents of PBL teaching method. Compared with traditional teaching method, TBL teaching method needs more teaching resources, teaching equipment and places. In view of increasing number of medical students, teaching facilities and teaching conditions cannot satisfy teaching demand. All these hinder smooth implementation of TBL teaching method. The faculty is weak. TBL teaching method pays attention to group cooperation. Each class may include 5-7 students. However, most medical colleges adopt large-class teaching mode. It is difficult to divide students in numerous classes, and each group should be equipped with a tutor. Thus, the demand for teachers is large. Even if some teachers own TBL teaching theory and skills, they lack teaching experience and often encounter some problems which difficult to solve. TBL class hour calculation is insufficient, and TBL teaching involves many contents, such as case preparation, assignment correction, questionnaire survey and students reporting. But these contents need to be completed in one lesson, which needs sufficient class hours. The teaching effect cannot be reached, if the class hours are not sufficient. 


\section{Measures to Perfect TBL Teaching Method}

From the perspective of medical science, TBL teaching method is applicable to the students in the foundation stage. The students in clinical practice stage can first use PBL teaching method and then adopt TBL teaching method to achieve combination of theory and practice and prevent the situation of valuing practice and ignoring theory. For the difficult knowledge with strong theoretical property, TBL teaching method can be used to deepen cognition of clinical knowledge, find out the knowledge point faster and distinguish clinical relations. Additionally, TBL teaching method and PBL teaching method can offset and refer to each other to jointly promote improvement of teaching quality.

1. To formulate teaching programme and prepare TBL teaching material

Elaborate preparation of teaching programme can start from teaching material content, teaching requirement and teaching activity. The teaching programme can lead and guide teaching activity. It is an important method and guarantee of talent training. The teaching programme should be formulated in combination of features and requirements of different disciplines, and teaching materials should be prepared in an organized and refined way. Teachers with mature experience in the field need to prepare the teaching material. The following contents should be reflected: expand scope of knowledge, intensify basic knowledge, respect differences of students, increase and decrease teaching contents, unify course contents, flexibly apply knowledge, conduct cutting-edge lecture and guide students to actively participate in course discussion.

To establish scientific and rational evaluation system

A scientific and rational teaching system is an important means to evaluate teaching methods. So far, even if TBL teaching method is gradually applied and promoted, discipline system still has a large diffidence compared with PBL teaching method. Scientific teaching evaluation system should be established in combination of teaching content, learning stage and students quality. Additionally, educational fund input should increase. To make sure TBL teaching method owns implementation foundation and conditions, fund and resource input should increase, such as providing more large-space TBL classroom, making references richer and supplying sufficient electronic education equipment. In addition, colleges should prepare sufficient class hours and actively encourage teachers to enhance design and development of TBL course.

To expand faculty

In view of very limited faculty, it is very important to enhance TBL faculty construction and expansion. The main approaches include the following: employ TBL teachers with rich experience; enhance training and education of young teachers; select the teachers with rich experience and strong learning ability; enhance teachers environment adaptation ability; choose excellent teachers to exchange and learn in famous colleges to make them own more all-round ability and expand the scope of knowledge.

\section{Conclusions}

In one word, TBL teaching method is a new teaching method. The application of TBL teaching method in college medical teaching can not merely facilitate students ability training and quality improvement, but also drive orderly implementation of medical teaching. As teaching research goes deep, TBL teaching method is gradually implemented and promoted in more colleges, and its teaching value in medical colleges becomes increasingly great. But, TBL teaching methods still has many shortcomings. More scientific and rational evaluation system should be established. It is also necessary to improve teaching quality and boost students comprehensive quality.

\section{Acknowledgments}

This paper is a part of 2015 educational scientific research project of Qiqihar Medical University; project name: exploration of medical Chinese teaching for overseas students based on TBL teaching mode; project No.: JY20151044 


\section{References}

[1] Meng Guiqin, Application Effect Evaluation of TBL Teaching Method in Teaching Basic Vocational Technology of Nurses. Chinese Journal of Practical Nursing, 2013,29(22):1-4.

[2] Mu Xiaoyun, Wang Yibo, Liang Bin et al., Study on Application of TBL Teaching Method Combining Learning Community in Teaching Medical Nursing. Nursing Research, 2015(11):1376-1377.

[3] Ren Mingxin, Cui Weigang, Deng Xiaohui et al., Specific Design and thought on TBL Teaching Method in Teaching Postgraduates Anatomy of Central Nervous System. Chinese Journal of Anatomy, 2012,35(6):839-840.

[4] Huang Li, Huang Suoyi, Lu Haifeng et al., Research and Practice of TBL Teaching Method and LBL TBL Teaching Method in Teaching Basic Chemistry. The Guide of Science \& Education, 2015(32):125-126,131.

[5] Dong Yan, Li Shuxia, Zhou Tao et al., Increasing Application of TBL Teaching Method in PBL for Tumor Postgraduate Teaching. Journal of Dalian Medical University, 2015(1):81-84. 